\title{
An investigation into students' difficulties in numerical problem solving questions in high school biology using a numeracy framework
}

\author{
Fraser J. Scott \\ Department of Pure and Applied Chemistry, University of Strathclyde, Glasgow, Scotland \\ For correspondence: fraser.j.scott@strath.ac.uk
}

\begin{abstract}
The 'mathematics problem' is a well-known source of difficulty for students attempting numerical problem solving questions in the context of science education. This paper illuminates this problem from a biology education perspective by invoking Hogan's numeracy framework. In doing so, this study has revealed that the contextualisation of mathematics within the domain of biology is not the main source of difficulty for students but rather more fundamental mathematical skills.
\end{abstract}

Keywords: Numeracy, Problem Solving, Biology Education, Mathematical Deficiency, The Mathematics Problem.

\section{Numerical Problem Solving in Biology Education}

\section{Problem Solving}

Problem solving is a fundamental skill that is necessary to effect learning from the level of novice to that of expert and to allow an expert to operate effectively at an advanced level (American Association for the Advancement of Science, 2011; National Academy of Science, 2011). Problem solving is defined as the application of basic operations in order to move the initial state of a system to its goal state (Newell \& Simon, 1972; Dunbar, 1998). This definition is very broad but this reflects the expansive nature of the literature on problem solving. However, two key features of problem solving can be identified as being significant to the research presented in this paper pertaining to numerical problem solving questions: level appropriateness; and, novelty.

In order to appropriately categorise a question as a "problem" it cannot be examined in isolation from its intended audience. It is a requirement that the question be developmentally appropriate for the students who are to undertake it before it can be considered a problem solving question (Lesh \& Zawojewski, 2007; Piaget \& Inhelder, 1975). For example, some students will progress through their Biology education at a different rate to their mathematical education, therefore at different points during this progression, their mathematical fluency will differ. A numerical biology question might thus be routine for a student late in their education whilst a student at an earlier stage in their education may find the very same question much more problematic. Thus it is possible for a question to be both a "problem" and a routine exercise, simultaneously.

Familiarity with a question influences its categorisation as a problem i.e. once the solution is known the question is no longer a problem. The necessity for novelty in describing a question as a problem was first discussed by Köhler in 1925 (Köhler, 1925) and many researchers have further emphasised this since (Polya, 1945 \& 1962; Schoenfeld, 1985; National Council of Teachers of Mathematics, 2000). Unfamiliar questions require a student to use higher order thinking skills to reason and provide a solution. It is the necessity of these skills that renders any automatic operation ineligible for problem solving status (Lester \& Kehle, 2003; Resnick \& Ford, 1981). In other words, if a question can be solved 
by an algorithm alone, without the application of higher order thinking skills, then it does not constitute a problem solving question but merely a routine exercise.

\section{Numerical Proficiency in Science}

Basic mathematical principals are an absolute necessity if one is to understand any scientific phenomena. However, it is widely recognised that High school students' lack a basic understanding of mathematical concepts and hence this negatively impacts their understanding of science. This observation has been the focus of much media attention (Royal Society of Chemistry, 2009a, 2012a-b) and has been under scrutiny from government advising bodies: a recent report from SCORE (Science Community Representing Education, 2010), a group of science regulatory bodies, has expressed concern that a significant proportion of the mathematical requirements of high school science courses are not assessed. Several initiatives by members of SCORE have been created as a consequence of this which are aimed at identifying and improving mathematical inadequacies (Royal Society of Chemistry, 2009b-c). The numerical problem solving inadequacies of students, and their impact, has been commented on within science education research for some time. The literature pertaining to physics and chemistry education research is well documented; however, that of biology education research is limited by comparison.

Most literature commentary relating to a lack of student mathematical proficiency within the field of biology education has been over the past 15 years (Gross, 2000; Bialek and Botstein, 2004). Gross (2000) asserted that mathematics and biology courses are often taught almost independently of each other at university level, even when obvious crossovers did exist. Gross suggests that this lack of contextualisation renders students with isolated knowledge constructs and hence students find it difficult to effectively transfer knowledge from one course to the other. Similarly, Hourighan and O'Donoghoue (2006) discovered that students enter mathematically demanding university level biology courses with a distinct lack of the requisite mathematical skills needed to effectively engage with the course. They too asserted that mathematics is taught in isolation to biology leaving students with no opportunity to explore the mathematical ideas in context and that this promoted a 'learned helplessness' within the student body. Bialek and Botstein (2004) argued that the biological sciences are now too complex to begin studying the interdisciplinary facets at a late stage and suggest that an integrated approach is required early on in education. Some specific negative outcomes of these disconnected learning approaches have also been investigated. A university level study by O'Shea (2003) found that Irish students significantly underperformed on non-routine mathematical tasks contextualised within biology questions. Similarly, Australian nursing students demonstrated basic mathematical errors during the calculation of drug concentrations (Eastwood et al., 2011). Moreover, a decade-long survey of plant physiology students, by Llamas et al. (2012), revealed persistent weaknesses in their abilities to answer quantitative questions.

\section{Mathematics in Context}

The literature pertaining to the use of mathematics in different contexts largely follows one of two lines of argument, either transfer of learning or situated cognition. The transfer of learning argument investigates the idea of knowledge gained in one context being transferrable to another context (Evans, 1999) and is the foundation on which education is built (Perkins, 1992). This idea of transfer is central to science education as the mathematical knowledge that students develop in the mathematics classroom is expected to be available for use in the science classroom (Schoenfeld, 1994). For knowledge to be transferred to a new context it must first be developed in the original context. For example, if students do not learn any mathematics in the mathematics classroom they will be unable to use mathematical knowledge in the science classroom. In a chemistry setting, Hoban, Finlayson and Nolan (2013) have suggested that many student difficulties arise due to insufficient mathematical understanding rather than an inability to transfer the knowledge. Transfer of knowledge has also been said to be improved if the instruction is well-designed in the primary context (Perkins and Salomon, 1988) yet some researchers are of the opinion that the transfer of learning is not necessarily as linear as it may seem. Boaler (1993) asserts that the context that knowledge is to be transferred into can significantly affect students' performance and that this phenomenon is underestimated; the alternative argument, situated cognition (Lave and Wenger, 1991) places more emphasis on this. 
It has been said that understanding and the context in which it occurs cannot be separated (Lave, 1988). Thus, the biological context in which one finds many mathematical concepts embedded requires a significant degree of attention since it is distinct from the mathematical context in which it was first learned. Brown, Collins and Duguid (1989) exemplify this when they assert that equation manipulation and use of algorithms, fundamental mathematical concepts, are not necessarily well used by students in novel contexts despite being confident in their use in a mathematics classroom. Furthermore, they argue that the abstract concept and the context in which it is learned are linked and thus one cannot expect efficient transfer to new contexts. The central theme in situated cognition is therefore to develop skills within the context they are to be used.

These two theories do not have to act in opposition and an alternative framework may assist to aid in the understanding of the use of mathematics in science education. This study will use Hogan's numeracy framework to further illuminate the 'mathematics problem'.

\section{Hogans' Numeracy Framework}

Hogan (2000) asserts that for one to be numerate in a particular situation one needs three types of knowledge: mathematical, contextual and strategic. Mathematical knowledge is defined as "the skills, techniques and concepts necessary to solve quantitative problems encountered in a real context" (Thornton \& Hogan, 2004a). These skills, techniques and contexts are first encountered by a secondary school student in the mathematics classroom. Students must first have familiarity with these mathematical concepts before they are able to use them in other domains such as the various mathematical areas of science. Without the prerequisite mathematical knowledge, a student will be unable to indentify the mathematics in a particular situation or use appropriate mathematical skills (Seirpinska, 1995).

Mathematical knowledge alone is not sufficient for one to be numerate as an understanding of the context in which the mathematics resides is crucial too (Hogan, 2000). A student with a comprehensive mathematical knowledge, will still encounter difficulties in solving a problem if they do not possess an understanding of what is being asked of them. At a basic level, contextual knowledge is an understanding of the language and terms used in a problem but at a more advanced level it is being able to understand the significance, meaning and perhaps inferences that the problem presents (Thornton \& Hogan, 2004b).

Possession of strategic knowledge is also key to being numerate. This is the ability to select and employ mathematical knowledge once the context of the problem has been understood (Perso, 2006; Hogan, 2000). In this regard, strategic knowledge serves to bring together both mathematical knowledge and contextual knowledge to give rise to a numerate individual. Checking that a solution makes sense is also part of strategic knowledge. Taken as a whole, Hogan's (2000) strategic knowledge is closely linked with metacognition.

\section{The Purpose of This Study}

This study aims to investigate the difficulties that students display when answering numerical problem solving questions in high school level biology. The numerical problem solving questions that are under investigation are those commonly encountered by candidates sitting the National 5 and Higher biology courses of the Scottish education system. The level of mathematical skill required in these questions is far lower than the level of biology that might be required to understand the context. Moreover, although the questions are contextualised within a biology setting, they often do not require any understanding of biology to answer - they are in essence mathematical questions covering such concepts as averages, percentage increase or decrease, ratios and data interpretation. These mathematical skills are covered far earlier in the students' education, generally in primary school (about 4 years earlier), and these students are expected to be able to have understanding of far more difficult mathematical concepts; the same levels of mathematics in the Scottish curriculum cover 
such topics as trigonometry, vectors and calculus. It is thus important to investigate the origin of the difficulties that students encounter.

\section{Research Questions}

This study will use an empirical design to investigate numerical problem solving questions in high school level biology. Two research questions have been identified:

(1) Is there evidence of student difficulties in answering numerical problem solving questions in biology?

(2) What does an examination of students' performance on numerical problem solving questions in biology, as analysed using Hogan's framework of numeracy, reveal about the nature of student difficulties?

\section{Research Methodology}

\section{Situational and Structural Analysis}

In order to design an activity to explore students' understanding of numerical problem solving questions it was first necessary to conduct a review of the types of question encountered by students following both the Scottish National 5 and Higher biology courses. This situational and structural analysis of the problem domain was carried out as per Scott (2015) in which situational refers to the identification of biology contexts where numerical problem solving skills are used and structural refers to the examination of the specific numerical skills that are required to solve such problems. Both of these stages involved discourse with multiple, practising high school biology teachers. This analysis identified five distinct question types and these are listed in table 1 along with an example of each. A similar situational and structural analysis has been carried out previously by the author on a slightly smaller problem domain, that of only the Higher biology course (Scott, 2015). This previous analysis similarly identified 'percentage', 'ratio', 'percentage increase or decrease' and 'proportion' as question types; however, the 'average' question type was not found in the previous analysis. Since the test instrument that was to be designed using the situational and structural analysis was to be delivered to students following both the National 5 and Higher courses, it was decided to only use question types of the lower level course. Thus the 'proportion' question type will not be considered further in this study.

Each of these questions first involves extracting the relevant numerical details from either a graph or table before the appropriate mathematical skills can be used to solve the question.

Table 1. Question types and examples.

\begin{tabular}{|c|c|c|c|c|c|c|}
\hline Question & \multicolumn{6}{|c|}{ Example } \\
\hline \multirow{10}{*}{ Average } & \multirow{2}{*}{\multicolumn{6}{|c|}{$\begin{array}{l}\text { Six pitfall traps were set in a woodland to sample the invertebrates liv } \\
\text { The results are shown in the table below. }\end{array}$}} \\
\hline & & & & & & \\
\hline & Pitfall Trap & \multicolumn{5}{|c|}{ Number of each type of invertebrate caught } \\
\hline & & Spiders & Woodlice & Beetles & \begin{tabular}{|l} 
Snails \\
\end{tabular} & Earthworms \\
\hline & 1 & 6 & 2 & 2 & 0 & 0 \\
\hline & 2 & 8 & 5 & 5 & 3 & 0 \\
\hline & 3 & 7 & 0 & 3 & 2 & 1 \\
\hline & 4 & 4 & 3 & 7 & 3 & 0 \\
\hline & 5 & 9 & 3 & 0 & 1 & 1 \\
\hline & 6 & 8 & 1 & 4 & 1 & 0 \\
\hline
\end{tabular}

Calculate the average number of spiders found per trap.

Percentage The table shows the masses of various substances in the glomerular filtrate and in the urine over a period of 24 hours. 
Ratio

\begin{tabular}{|l|c|c|}
\hline Substance & $\begin{array}{c}\text { Mass in } \\
\text { glomerular } \\
\text { filtrate }(\mathrm{g})\end{array}$ & $\begin{array}{c}\text { Mass in } \\
\text { urine } \\
(\mathrm{g})\end{array}$ \\
\hline Sodium & $600 \cdot 0$ & $6 \cdot 0$ \\
\hline Potassium & $35 \cdot 0$ & $2 \cdot 0$ \\
\hline Uric acid & $8 \cdot 5$ & $0 \cdot 8$ \\
\hline Calcium & $5 \cdot 0$ & $0 \cdot 2$ \\
\hline
\end{tabular}

What percentage of the total mass of substances found in the urine is potassium? Leaf rust is a fungus which grows when its spores land on leaves. The fungus spreads over leaf surfaces causing damage. Single leaves from four different species of cottonwood tree were sprayed with identical volumes of a suspension of rust fungus spores. After 3 days the percentage of leaf area with fungal growth was measured. The tannin content in these leaves was also measured.

\begin{tabular}{|c|c|c|}
\hline Cottonwood species & $\begin{array}{c}\text { Percentage leaf area with } \\
\text { fungal growth after 3 days }\end{array}$ & $\begin{array}{c}\text { Tannin content in leaves } \\
\text { (mg per g of leaf dry mass) }\end{array}$ \\
\hline Black & $2 \cdot 4$ & $40 \cdot 6$ \\
\hline Eastern & $11 \cdot 4$ & $3 \cdot 9$ \\
\hline Narrow-leafed & $4 \cdot 3$ & $11 \cdot 7$ \\
\hline Swamp & $3 \cdot 2$ & $15 \cdot 6$ \\
\hline
\end{tabular}

Express as the simplest whole number ratio, the tannin content in the leaves of the eastern cottonwood, narrow-leafed cottonwood and swamp cottonwood.

Percentage Increase or decrease

Proportion
The graph below shows the body mass of a human male from birth until 22 years

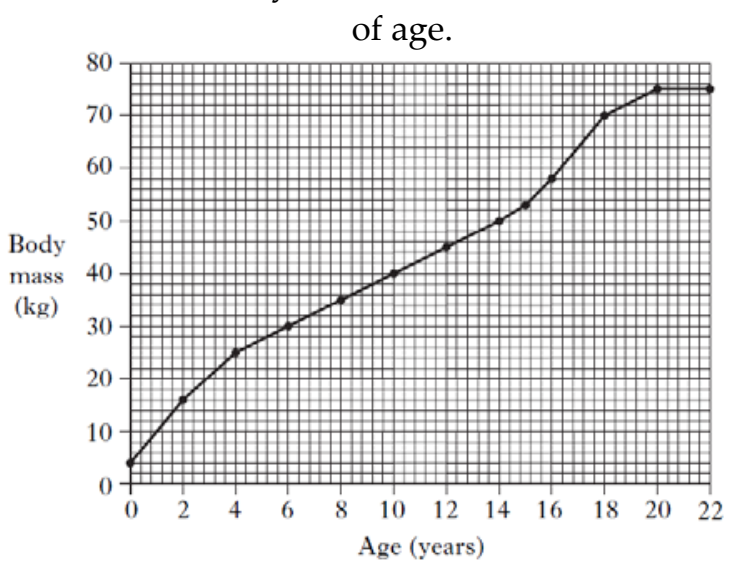

Calculate the percentage increase in body mass in the last 8 years of the study. The graph below shows how the concentration of insulin in the blood varies with the concentration of glucose in the blood.

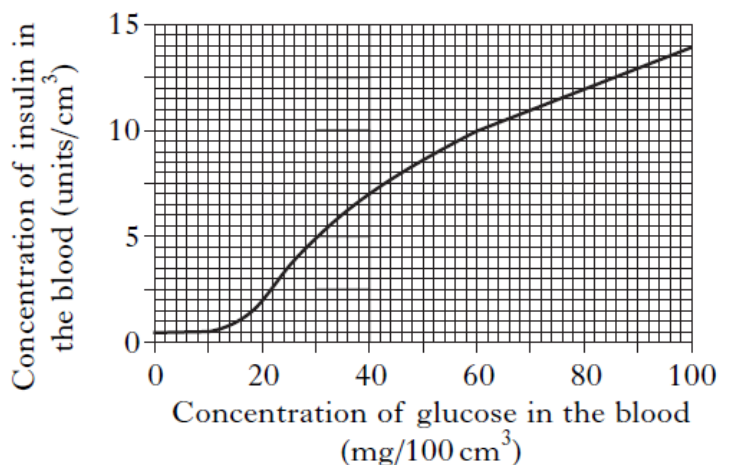

What total mass of glucose would be present at an insulin concentration of 10 
units/cm3, in an individual with 5 litres of blood?

During the situational analysis of the four types of numerical problem solving questions it became apparent that the use of the term 'problem' in the context of these questions required some attention. The more experienced scientist may see these questions as nothing more than simple mathematical 'exercises' yet it is thought that a number of factors contribute to their classification as 'problems' within this context. Since the mathematics has been contextualised within a biology setting these questions are somewhat unfamiliar and more than routine mathematics exercises. Furthermore, although these questions are part of the Scottish biology curriculum, many biology teachers view these as questions as being of the problem solving type, and refer to them as such, so often do not 'teach' them like they would the rest of the curriculum. Biology teachers thus rely on their students' prior understanding of mathematics to solve these questions themselves. These factors indicate that the lack of familiarity students have with these questions in a biology setting contributes to their categorisation from 'exercises' to 'problems'. The author acknowledges that the classification of these questions as 'problems' or 'exercises' may be a debatable one.

The question types identified through the situational and structural analysis were then used to design the test instrument, details of which are described in the next section.

\section{Test Instrument Design and Implementation}

A test instrument design was required that would elucidate a number of pieces of information. First, the four different question types, average, percentage, ratio and percentage increase, needed to be incorporated. Second, the effect of the biological context of these numerical problem solving questions wished to be explored and this required two series of analogues questions each covering all four question types: one series of biology questions; and, one series of mathematical questions that are identical to the biology question series but with no biological context. The situational and structural analysis also revealed that the biology questions expected of Scottish high school students can involve either the extraction of information from a table or a graph. It was thought that this may be an important aspect to explore and to achieve this a third series of questions was necessary.

The test instrument thus contained three series of questions: mathematics; biology (table); and, biology (graph). The mathematics and biology (table) question series each involved extracting information from a table and hence comparison of these could reveal information about the effect of the biological context. The biology (graph) question series involved extracting information from a graph and so could be compared to the biology (table) question series to yield information on the differences between questions involving graphs and tables. Each of the three series contained the four question types. The test instrument can be found in the supplementary information.

\section{Study Setting and Participants}

This study was carried out in a high school in Scotland during the run up to the national exams thus none of the content of the test instrument would be considered new material to the participating students. Three Higher Biology classes participated in this study each composed of mainly 5 th year students, age 16/17, and a very small proportion of 6th year students, age 17/18 to give a total of 48 students that participated from this level. Additionally, four National 5 biology classes participated each composed of 4 th year students, age 15/16, to give a total of 71 students that participated from this level. The classes were of mixed ability, sex and had different teachers.

Permission was obtained from the head teacher of the school before this research was carried out. Pupils were required to sign a research consent form to allow the data generated to be analysed; however, every pupil in the classes participated in the activity. 


\section{Data Analysis}

\section{Analysis of Overall Performance}

Students' responses to the test instrument were scored in a binary fashion as either correct or incorrect. This generated a correct answer rate for each question type. The different question types also made two series of four matched pairs, one comparing biology (table) and mathematics (table) questions and the other comparing the biology (table) and biology (graph) questions; as such, a McNemar test was employed.

\section{Error Analysis}

The analysis involved the deductive coding of the student' s erroneous answers using Hogan's (2000) framework which produced the three codes of mathematical, contextual and strategic knowledge. Coding of the data was conducted with the help of an experienced biology educator with codes continually checked to ensure consistency of meaning. Once coded, the percentages of erroneous answers appearing in each category, and for each question type, was calculated.

\section{Results and Discussion}

\section{Examination of Students Overall Performance}

The National 5 students' performance on the test instrument is summarised in table 2. For the mathematics questions, students performed best on the ratio and average question types $(79.7 \%$, and $78.4 \%$, respectively) followed by the percentage question type $(56.8 \%)$ and finally the percentage increase question type (9.5\%). For the biology (table) questions the pattern is similar but with the ratio and average question types the other way about: average $(78.4 \%)$, ratio $(75.7 \%)$, percentage (56.8\%) and finally percentage increase $(9.5 \%)$. The biology (graph) questions have noticeably lower scores but follow a similar patter to the mathematics questions: ratio $(62.2 \%)$ average $(52.7 \%)$, percentage $(23.0 \%)$ and finally percentage increase $(1.4 \%)$. Students' performance in the biology (graph) question series was approximately $20 \%$ lower than their performance on either the biology (table) or mathematics question series (34.8\% compared to $53.8 \%$ and $56.1 \%$, respectively).

These data would seem to suggest that the average and ratio question types are most easy followed by the percentage question type with the percentage increase question type being the most difficult by a considerable margin. It is perhaps worth reflecting on the students' performance on the percentage increase questions: the highest correct answer rate was only $9.5 \%$ for the mathematics question series and the lowest was $1.4 \%$ for the biology (graph) question series.

Table 2. National 5 students' scores on different question types.

\begin{tabular}{cccc}
\hline Question Type & $\begin{array}{c}\text { Mathematics } \\
\%\end{array}$ & $\begin{array}{c}\text { Biology (Table) } \\
\%\end{array}$ & $\begin{array}{c}\text { Biology (Graph) } \\
\%\end{array}$ \\
\hline Average & 78.4 & 78.4 & 52.7 \\
Ratio & 79.7 & 75.7 & 62.2 \\
Percentage & 56.8 & 52.7 & 23.0 \\
Percentage & 9.5 & 8.2 & 1.4 \\
Increase & & 53.8 & 34.8 \\
AVERAGE & 56.1 & & \\
\hline
\end{tabular}

The Higher students' performance on the test instrument is summarised in table 3. For the mathematics questions, students performed best on the average question type (87.5\%) followed by the percentage question type $(83.3 \%)$, the ratio question type $(77.1 \%)$ and finally the percentage increase question type $(41.7 \%)$. For this question series, the percentage question type has moved from third to second easiest in comparison to the National 5 data previously presented. For the biology (table) questions the pattern is again similar to the National 5 data: average $(93.8 \%)$, ratio $(89.6 \%)$, percentage (77.1\%) and finally percentage increase (50.0\%). The biology (graph) questions have noticeably lower 
scores but follow a similar patter to the biology (table) questions: average $(70.1 \%)$, ratio $(62.5 \%)$, percentage $(52.1 \%)$ and finally percentage increase $(27.1 \%)$. Students' performance in the biology (graph) question series was approximately $20 \%$ lower than their performance on either the biology (table) or mathematics question series (53.0\% compared to $77.6 \%$ and $72.4 \%$, respectively) which is in line with the National 5 data.

Similar to the National 5 data, the Higher data would seem to suggest that the average question type is most easy followed by the ratio question type, the percentage question type and the percentage increase question type being the most difficult, again by a considerable margin. Although the trend in the mathematics question series sees the percentage and ratio question types swapped in difficulty. Although not as pronounced as the National 5 data set, the scores for the percentage increase question type are worth highlighting in the Higher data set too: the highest correct answer rate was $50 \%$ for the biology (table) question series and the lowest was 27.1\% for the biology (graph) question series.

Table 3. Higher students' scores on different question types.

\begin{tabular}{cccc}
\hline Question Type & $\begin{array}{c}\text { Mathematics } \\
\%\end{array}$ & $\begin{array}{c}\text { Biology (Table) } \\
\%\end{array}$ & $\begin{array}{c}\text { Biology (Graph) } \\
\%\end{array}$ \\
\hline Average & 87.5 & 93.8 & 70.1 \\
Ratio & 77.1 & 89.6 & 62.5 \\
Percentage & 83.3 & 77.1 & 52.1 \\
Percentage & 41.7 & 50.0 & 27.1 \\
Increase & 72.4 & 77.6 & 53.0 \\
AVERAGE & & & \\
\hline
\end{tabular}

The three series of questions were then compared using a McNemar analysis on the pairwise data. Both the National 5 and the Higher data display similar results as can be seen in table 4 and table 5 . The p-values for all the analyses for the mathematics and biology (table) questions are all indicative of no statistically significant difference in performance on any of the question types at either level. This is in direct contrast to the comparison between the biology (table) and biology (graph) question series which indicates that all but the percentage increase question at the National 5 level are statistically significant with $\mathrm{p}$-values less than 0.05 . The $\mathrm{p}$-value for the percentage increase question at the National 5 level is 0.0736 so whilst low is not statistically significant at the $95 \%$ confidence level. This is likely a consequence of the poor performance in all question series for this question type and a concomitantly small sample size for pairwise success.

Table 4. McNemar analysis of National 5 students' performance between question types.

\begin{tabular}{ccc}
\hline & \multicolumn{2}{c}{ p-Values } \\
\cline { 2 - 3 } Question Type & $\begin{array}{c}\text { Mathematics and } \\
\text { Biology (Table) }\end{array}$ & $\begin{array}{c}\text { Biology (Table) and } \\
\text { Biology (Graph) }\end{array}$ \\
\hline Average & 0.8383 & 0.0023 \\
Ratio & 0.6464 & 0.0412 \\
Percentage & 0.6056 & 0.0001 \\
Percentage & 1.0000 & 0.0736 \\
Increase & & \\
\hline
\end{tabular}

Table 5. McNemar analysis of Higher students' performance between question types.

\begin{tabular}{ccc}
\hline \multirow{2}{*}{ Question Type } & \multicolumn{2}{c}{$\mathrm{p}$-Values } \\
\cline { 2 - 3 } & $\begin{array}{c}\text { Mathematics and } \\
\text { Biology (Table) }\end{array}$ & $\begin{array}{c}\text { Biology (Table) and } \\
\text { Biology (Graph) }\end{array}$ \\
\hline Average & 0.5050 & 0.0055 \\
Ratio & 0.1814 & 0.0059
\end{tabular}




$\begin{array}{ccc}\text { Percentage } & 0.5465 & 0.0139 \\ \begin{array}{c}\text { Percentage } \\ \text { Increase }\end{array} & 0.4227 & 0.0098\end{array}$

Two important conclusions can be made from these comparisons. First, there is no difference in students' performance between the mathematics and biology (table) question series and thus the notion of the biology context being a source of difficulty for the students is not supported by evidence in this study. Second, the source of the data to be used in a question makes an important contribution to its difficulty: questions involving extraction of data from a graph are more challenging than those where the data is to be extracted from a table.

\section{Error Analysis}

Each incorrect response was categorised according to Hogan's numeracy framework. To illustrate the categorisation process a number of the student errors will be examined below. Figure 1 shows a student's attempt at a ratio question type from the biology (table) question series that has been categorised as a mathematical error, along with the question. In this answer, the student has success fully extracted the information from the table and carried out a summation of values to achieve the initial ratio of 14:21. The student appears to have recognised that this ratio requires simplification, as suggested in the question, but does not have the mathematical knowledge to effect such a simplification.

\section{Q6 Six pitfall traps were set in a woodland to sample the invertebrates living there.}

The results are shown in the table below.

\begin{tabular}{|l|l|l|l|l|l|}
\hline \multirow{3}{*}{ Pitfall Trap } & \multicolumn{5}{|c|}{ Number of each type of invertebrate caught } \\
\cline { 2 - 6 } & Spiders & Woodlice & Beetles & Snails & Earthworms \\
\hline 1 & 6 & 2 & 2 & 0 & 0 \\
\hline 2 & 8 & 5 & 5 & 3 & 0 \\
\hline 3 & 7 & 0 & 3 & 2 & 1 \\
\hline 4 & 4 & 3 & 7 & 3 & 0 \\
\hline 5 & 9 & 3 & 0 & 1 & 1 \\
\hline 6 & 8 & 1 & 4 & 1 & 0 \\
\hline
\end{tabular}

a) Calculate the average number of spiders found per trap.

b) Express the total numbers of woodlice and beetles trapped as a simple whole number ratio.

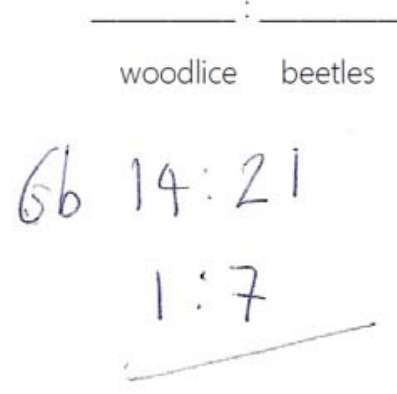

Figure 1. A students attempt at $\mathrm{Q} 6 \mathrm{~b}$, a ratio question from the biology (table) question series.

Figure 2 shows a student's attempt at Q6a, an average question type from the biology (table) question series that has been categorised as a contextual error (the question can be found in figure 1). Here, the student appears to have considered spiders, woodlice and beetles all to be types of spider; the numbers they add together in the first line of their working is the sum of all three categories. After this error, they successfully carry out the rest of the calculation. 


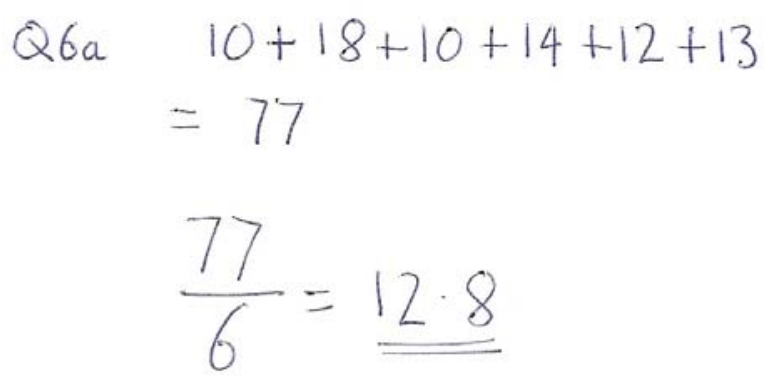

Figure 2. A students attempt at an average question from the biology (table) question series.

Figure 3 shows a student's attempt at Q8a, a percentage increase question type from the biology (graph) question series that has been categorised as a strategic error, along with the question. The student has successfully extracted the information from the graph and is able to calculate that the new value at 8 hours is $300 \%$ of the initial value; however, they have failed to interpret the overall question correctly and have not calculated the percentage increase.

Q8 The graph below shows the growth curve of a population of bacteria in a fermenter at $30^{\circ} \mathrm{C}$ over a

24-hour period.
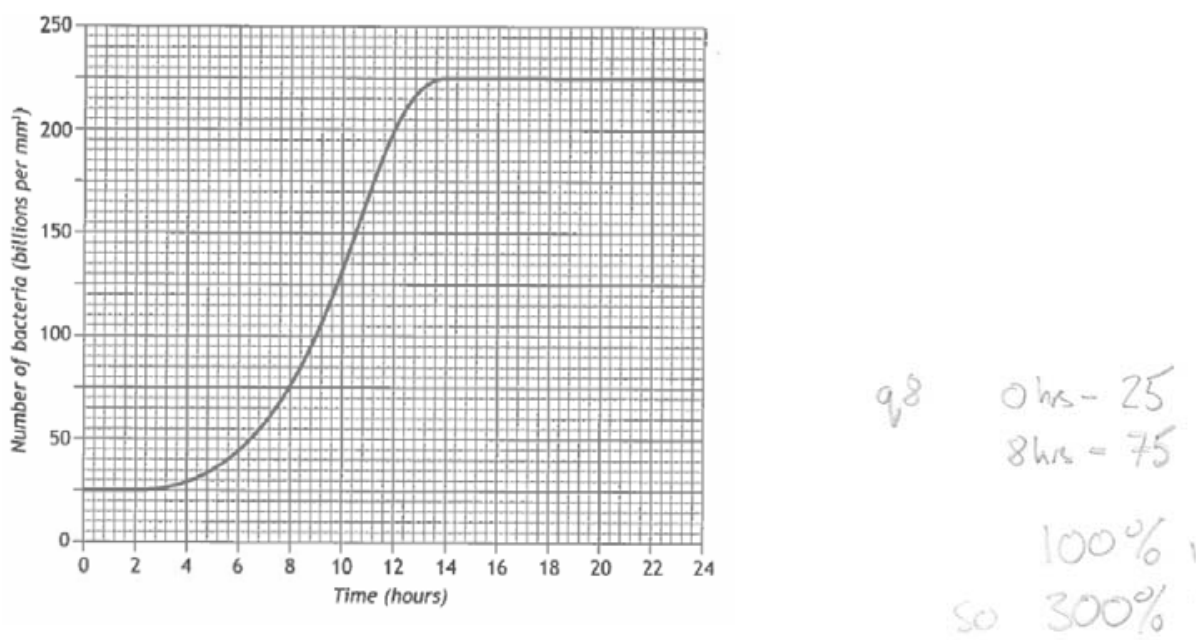

a) Calculate the percentage increase in the number of bacteria over the first 8 hours.

Figure 3. A students attempt at a percentage increase question from the biology (graph) question series.

Figure 4 contains a histogram illustrating the overall distribution of the categories across errors at National 5 and Higher and the individual results for each questions series and question type are shown in table 6. 


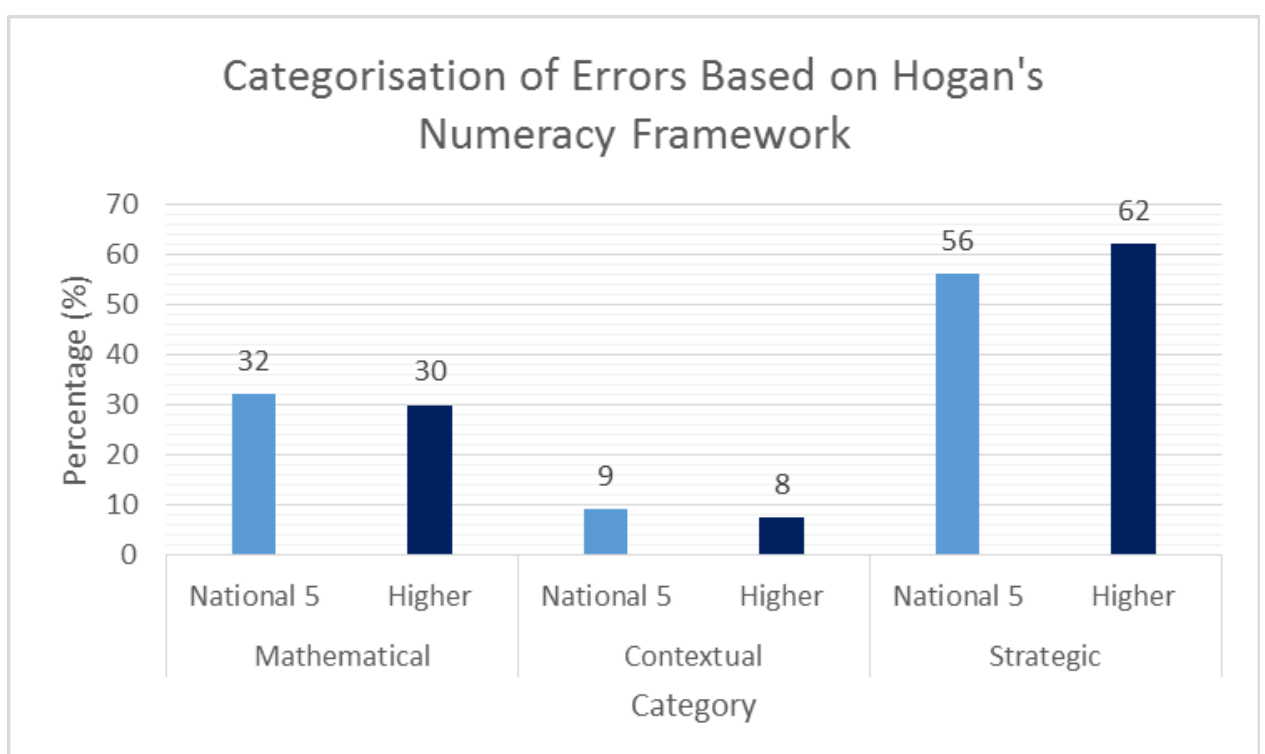

Figure 4. Categorisation of National 5 and Higher student errors according to Hogan's numeracy framework.

Table 6. Categorisation of National 5 and Higher student errors according to Hogan's numeracy framework.

\begin{tabular}{|c|c|c|c|c|c|c|c|}
\hline \multirow[b]{2}{*}{$\begin{array}{l}\text { Question } \\
\text { Series }\end{array}$} & \multirow[b]{2}{*}{ Question Type } & \multicolumn{2}{|c|}{ Mathematical } & \multicolumn{2}{|c|}{ Contextual } & \multicolumn{2}{|c|}{ Strategic } \\
\hline & & National 5 & Higher & $\begin{array}{c}\text { National } \\
5\end{array}$ & Higher & $\begin{array}{c}\text { National } \\
5\end{array}$ & Higher \\
\hline \multirow{4}{*}{ 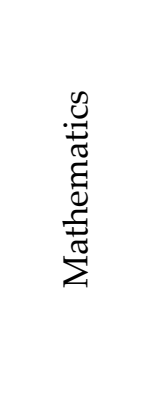 } & Average & $\begin{array}{c}33 \% \\
(N=15)\end{array}$ & $\begin{array}{c}33 \% \\
(N=6)\end{array}$ & $\begin{array}{c}7 \% \\
(N=15)\end{array}$ & $\begin{array}{c}17 \% \\
(N=6)\end{array}$ & $\begin{array}{c}60 \% \\
(N=15)\end{array}$ & $\begin{array}{c}50 \% \\
(N=6)\end{array}$ \\
\hline & Ratio & $\begin{array}{c}36 \% \\
(N=14)\end{array}$ & $\begin{array}{c}45 \% \\
(N=11)\end{array}$ & $\begin{array}{c}14 \% \\
(N=14)\end{array}$ & $\begin{array}{c}18 \% \\
(N=11)\end{array}$ & $\begin{array}{c}50 \% \\
(N=14)\end{array}$ & $\begin{array}{c}36 \% \\
(N=11)\end{array}$ \\
\hline & Percentage & $\begin{array}{c}38 \% \\
(N=21)\end{array}$ & $\begin{array}{c}50 \% \\
(N=8)\end{array}$ & $\begin{array}{c}14 \% \\
(N=21)\end{array}$ & $\begin{array}{c}0 \% \\
(N=8)\end{array}$ & $\begin{array}{c}48 \% \\
(N=21)\end{array}$ & $\begin{array}{c}50 \% \\
(N=8)\end{array}$ \\
\hline & $\begin{array}{l}\text { Percentage } \\
\text { Increase }\end{array}$ & $\begin{array}{c}31 \% \\
(N=64)\end{array}$ & $\begin{array}{c}26 \% \\
(N=27)\end{array}$ & $\begin{array}{c}5 \% \\
(N=64)\end{array}$ & $\begin{array}{c}7 \% \\
(N=27)\end{array}$ & $\begin{array}{c}64 \% \\
(N=64)\end{array}$ & $\begin{array}{c}67 \% \\
(N=27)\end{array}$ \\
\hline \multirow{4}{*}{ 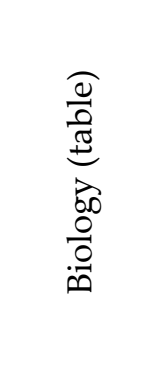 } & Average & $\begin{array}{c}40 \% \\
(N=15)\end{array}$ & $\begin{array}{c}33 \% \\
(N=3)\end{array}$ & $\begin{array}{c}7 \% \\
(N=15)\end{array}$ & $\begin{array}{c}0 \% \\
(N=3)\end{array}$ & $\begin{array}{c}53 \% \\
(N=15)\end{array}$ & $\begin{array}{c}66 \% \\
(N=3)\end{array}$ \\
\hline & Ratio & $\begin{array}{c}24 \% \\
(N=17)\end{array}$ & $\begin{array}{c}20 \% \\
(N=5)\end{array}$ & $\begin{array}{c}6 \% \\
(N=17)\end{array}$ & $\begin{array}{c}20 \% \\
(N=5)\end{array}$ & $\begin{array}{c}71 \% \\
(N=17)\end{array}$ & $\begin{array}{c}60 \% \\
(N=5)\end{array}$ \\
\hline & Percentage & $\begin{array}{c}29 \% \\
(N=34)\end{array}$ & $\begin{array}{c}27 \% \\
(N=11)\end{array}$ & $\begin{array}{c}6 \% \\
(N=34)\end{array}$ & $\begin{array}{c}0 \% \\
(N=11)\end{array}$ & $\begin{array}{c}35 \% \\
(N=34)\end{array}$ & $\begin{array}{c}73 \% \\
(N=11)\end{array}$ \\
\hline & $\begin{array}{l}\text { Percentage } \\
\text { Increase }\end{array}$ & $\begin{array}{c}29 \% \\
(N=65)\end{array}$ & $\begin{array}{c}29 \% \\
(N=24)\end{array}$ & $\begin{array}{c}6 \% \\
(N=65)\end{array}$ & $\begin{array}{c}8 \% \\
(N=24)\end{array}$ & $\begin{array}{c}65 \% \\
(N=65)\end{array}$ & $\begin{array}{c}63 \% \\
(N=24)\end{array}$ \\
\hline \multirow{4}{*}{ 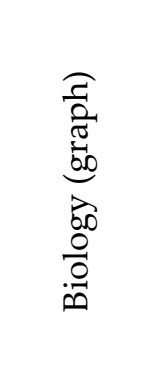 } & Average & $\begin{array}{c}38 \% \\
(N=34)\end{array}$ & $\begin{array}{c}36 \% \\
(N=14)\end{array}$ & $\begin{array}{c}21 \% \\
(N=34)\end{array}$ & $\begin{array}{c}14 \% \\
(N=14)\end{array}$ & $\begin{array}{c}41 \% \\
(N=34)\end{array}$ & $\begin{array}{c}50 \% \\
(N=14)\end{array}$ \\
\hline & Ratio & $\begin{array}{c}30 \% \\
(N=27)\end{array}$ & $\begin{array}{c}29 \% \\
(N=17)\end{array}$ & $\begin{array}{c}11 \% \\
(N=27)\end{array}$ & $\begin{array}{c}12 \% \\
(N=17)\end{array}$ & $\begin{array}{c}59 \% \\
(N=27)\end{array}$ & $\begin{array}{c}59 \% \\
(N=17)\end{array}$ \\
\hline & Percentage & $\begin{array}{c}33 \% \\
(N=55)\end{array}$ & $\begin{array}{c}27 \% \\
(N=22)\end{array}$ & $\begin{array}{c}9 \% \\
(N=55)\end{array}$ & $\begin{array}{c}0 \% \\
(N=22)\end{array}$ & $\begin{array}{c}58 \% \\
(N=55)\end{array}$ & $\begin{array}{c}73 \% \\
(N=22)\end{array}$ \\
\hline & $\begin{array}{l}\text { Percentage } \\
\text { Increase }\end{array}$ & $\begin{array}{c}33 \% \\
(N=70)\end{array}$ & $\begin{array}{c}26 \% \\
(N=34)\end{array}$ & $\begin{array}{c}11 \% \\
(N=70)\end{array}$ & $\begin{array}{c}6 \% \\
(N=34)\end{array}$ & $\begin{array}{c}56 \% \\
(N=70)\end{array}$ & $\begin{array}{c}68 \% \\
(N=34)\end{array}$ \\
\hline
\end{tabular}

The overall distribution of students' errors across the categories as depicted in figure 4 reveals a propensity for students' errors to be strategic in nature as demonstrated by $56 \%$ and $62 \%$ of students' errors being categorised as such for National 5 and Higher students, respectively. After strategic 
issues, students' errors were next likely to be of the mathematical category with $32 \%$ and $30 \%$ of National 5 and Higher students' incorrect responses, and finally, students' errors were classified as contextual with $9 \%$ and $8 \%$, respectively, for National 5 and Higher students.

A detailed examination of the percentage of each categorisation across each questions series and question type (table 6) echoes the overall distribution. This is true for all questions except for the ratio question type in the mathematics question series which sees the mathematical category higher than the strategic category for the Higher students' errors and the percentage question type, also in the mathematics question series, where the mathematical and strategic categories are equal in magnitude. The analysis of these data would suggest that the contextual knowledge of these questions is not the main contributor to any difficulties students may have with numerical problem solving questions. Mathematical knowledge and strategic knowledge appear to be areas of greater difficulty for students in this study.

\section{Conclusions}

This study sought to investigate the difficulties students have with numerical problem solving questions in high school biology. The first research question asked if there was any evidence of student difficulties in answering numerical problem solving questions in biology. The examination of students overall performance revealed that National 5 students could be said to have difficulties answering percentage and percentage increase questions: only around $50 \%$ of these students were correct in their answers for the percentage questions and less than $10 \%$ were correct for the percentage increase questions. The higher students displayed similar difficulties with both the percentage and the percentage increase questions being the least well answered. The percentage questions were much better answered for the Higher students with the correct answer rate being in the region of $75 \%$; however, one could argue that calculating a percentage should be such a simple operation for students who are expected to be able to deal with mathematical concepts such as calculus and that a score of $75 \%$ is still rather low. Again the Higher students' performance on the percentage increase questions was greater than the National 5 students, having reached around $50 \%$ but still low enough to be identified as a problem area. Considering the National 5 and Higher data as a whole, it appears that percentage and percentage increase questions are areas of difficulty for students in high school biology.

The comparison of the biology (table) and biology (graph) questions revealed that students have much greater difficulty correctly answering the graph questions. This is likely due to the greater difficulty students have with extracting the relevant information from a graph, rather than a table, to be used in answering the question. This effect, coupled with the previous assertion of students' difficulty in percentage increase questions, is neatly exemplified by the performance in the percentage increase question in the biology (table) question series: only 1 out of the 71 students managed to answer this question correctly. Graph reading can thus be identified as a problem area for students carrying out numerical problem solving questions.

The second research question asked if an examination of students' performance on numerical problem solving questions in biology using Hogan's framework of numeracy could reveal anything about the nature of student difficulties. This analysis has shown that students' errors can be categorised more commonly as a deficiency in mathematical knowledge or strategic knowledge and that a lack of contextual knowledge is least likely to be an issue for the majority of students. It has been established in the literature that the transfer of mathematical knowledge to the sciences is difficult for students; however, this is most often attributed to the difficulties students have in using the mathematics in the unfamiliar context (Boaler, 1993). The findings in this study suggest that the biology context of the numerical problem solving questions is not the main source of difficulty but mathematical knowledge and strategic knowledge, the other aspects of numeracy, are the main problems; these are both concepts that are primarily learned in the mathematics classroom. This is an important finding as it serves to indicate students' lack of mathematical preparation prior to entering the biology classroom. So whilst biology educators are likely in the best place to teach biology 
numeracy, due to the contextual requirement, it appears they are hindered by students' under developed mathematical and strategic knowledge from the mathematics classroom.

Overall, the major findings of this study can be summarised as follows:

(1) Students have most difficulty with percentage questions and percentage increase questions.

(2) Students find it more difficult to extract information from graphs than tables.

(3) The biological context of these questions is not the main source of difficulty: both a lack of mathematical and strategic knowledge are greater sources of difficulty.

\section{Limitations of this Study}

The cohort of students who participated in this study were drawn from only one school and as a result of this there may be a bias in the conclusions drawn from this study. The school which participated in this study usually performs well above average in national examinations and so one could speculate that the errors and issues identified here are a subset of those that exist in general and that there are others not identified here; however, it is likely that the errors identified here are present more generally and are thus a useful finding. As a consequence of the study taking place in only one school, the sample size was small, although statistically significant results were obtained. Despite these limitations, the findings of this study are still thought to represent a valuable contribution to the limited literature on the subject of mathematics in science education.

\section{Implications for the Teaching of Biology}

The research has highlighted a number of specific areas relating to numerical problem solving questions in high school biology that cause difficulties for students. With these identified it is hoped that biology educators can utilise this information when teaching relevant areas of high school biology courses. With mathematical knowledge and strategic knowledge being identified as the major contributors to students' difficulties it is thought that these issues may well have developed in the mathematics classroom and thus greater emphasis should be placed on learning these during students' mathematical education. However, this does not ameliorate the present problem and thus mathematics educators and biology educators should work together to develop a solution.

\section{Acknowledgements}

The author would like to thank Morag Findlay for her significant assistance in the preparation of this manuscript.

\section{References}

American Association for the Advancement of Science (2011). Vision and Change in Undergraduate Biology Education: A Call to Action, Washington, DC.

Bialek, W. and Botstein, D. (2004). Introductory science and mathematics education for 21st-century biologists. Science. 303, 788-790.

Boaler, J. (1993). The role of contexts in the mathematics classroom: Do they make the mathematics more "real"? For the Learning of Mathematics, 13(2), 12-17.

Brown, J. S., Collins, A. and Duguid, P. (1989) Situated cognition and the culture of learning, Educational Researcher, 18(1), 32-42.

Dunbar, K. (1998). Problem solving. In W. Bechtel, \& G. Graham (Eds.). A companion to Cognitive Science (pp. 289-298). London: Blackwell.

Eastwood, K.J., Boyle, M.J., Williams, B. \& Fairhall, R. (2011). Numeracy skills of nursing students. Nurse Educ. Today, 31, 815818.

Evans, J., (1999). Building bridges: Reflections on the problem of transfer of learning in mathematics, Educational Studies in Mathematics, 39(1), 23-44.

Gross, L.J. (2000). Education for a biocomplex future. Science, 28, 807.

Hoban, R. A., Finlayson, O.E. and Nolan, B .C. (2013). Transfer in chemistry: a study of students' abilities in transferring mathematical knowledge to chemistry. International Journal of Mathematical Education in Science and Technology, 44, 1, 2013.

Hogan, J., (2000), Numeracy across the curriculum, Australian Mathematics Teacher, 56(3), 17-20. 
Hourighan, M. and O'Donoghue, J. (2006). Mathematical Under-Preparedness: The Influence of the Pre-Tertiary Mathematics Experience on Students' Ability to Make a Successful Transition to Tertiary Level Mathematics Courses in Ireland. International Journal of Mathematical Education in Science and Technology, 38 (4), pp. 461-476.

Köhler, W. (1925). The mentality of apes. New York: Harcourt Brace \& World.

Lave, J. (1988). Mind, mathematics, and culture in everyday life, Cambridge, UK: Cambridge University Press.

Lave, J. and Wenger, E. (1991). Situated learning: Legitimiate peripheral participation, Cambridge, UK: Cambridge University Press.

Lesh, R., \& Zawojewski, J. (2007). Problem-solving and modeling. In F. Lester (Ed.), Second handbook of research on mathematics teaching and learning (pp. 763-804). Reston, VA: NCTM.

Lester, F. K., \& Kehle, P. E. (2003). From problem-solving to modeling: The evolution of thinking about research on complex mathematical activity. In R. Lesh, \& H. Doerr, (Eds.), Beyond constructivism: Models and modeling perspectives on mathematics problem solving, learning, and teaching (pp. 501-518). Mahwah, NJ: Lawrence Erlbaum Associates.

Llamas, A., Vila, F., Sanz, A. (2012). Mathematical skills in undergraduate students. A ten-year survey of a plant physiology course. Biosci Educ., 19.

National Academy of Science (2011). The Current Status and Future Direction of Biology Education Research, Washington, DC: National Academies of Science Press.

National Council of Teachers of Mathematics. (2000). Principles and standards for school mathematics. Reston, VA: National Council of Teachers of Mathematics.

Newell, A. and Simon, H.A. (1972). Human problem solving. Englewood Cliffs, NJ: Prentice-Hall.

O'Shea, J.P. (2003). Mathematical Problem Solving in the Senior Primary School: An Investigation into the Beliefs and Experiences of Class Teachers. MEd thesis, University of Limerick, Ireland.

Perkins, D. N. and Salomon, G. (1988). Teaching for transfer, Educational Leadership, 46(1), 22-32.

Perso, T. (2006). Teachers of mathematics or numeracy? Australian Mathematics Teacher, 62(2), 36-40.

Piaget, J., \& Inhelder, B. (1975). The origin of the idea of chance in children. London: Routledgate \& Kegan Paul.

Polya, G. (1945). How to Solve It. Princeton, NJ: Princeton University Press.

Polya, G. (1962). Mathematical discovery: On understanding, learning and teaching problem solving: Volume I. New York: John Wiley and Sons, Inc.

Resnick \& Ford, 1981). The psychology of mathematics instruction. Hillsdale, NJ: Lawrence Erlbaum Associates.

Royal Society of Chemistry, (2009a). www.rsc.org/images/ACMERSCResponse_tcm18-170564.pdf, date accessed 10/11/11.

Royal Society of Chemistry, (2009b). http://www.rsc.org/images/ Bulletin10_tcm18-134605.pdf, date accessed 10/11/11.

Royal Society of Chemistry, (2009c). http://discovermaths.rsc.org, date accessed 10/11/11.

Royal Society of Chemistry, (2012a). Is Maths to Blame? Education in Chemistry, 49(5), 7.

Royal Society of Chemistry, (2012b). Criticism of maths in chemistry grows. Education in Chemistry, 49(4), 3.

Scott, F. (2014). A simulated peer-assessment approach to improving student performance in chemical calculations. Chem. Educ. Res. Pract., 15, 568-575.

Scott, F. (2015). A simulated peer-assessment approach to improve students' performance in numerical problem solving questions in high school biology. J. Bio. Ed, in press.

Schoenfeld, A. H. (1985). Mathematical problem solving. New York: Academic Press.

Schoenfeld, A. H. (1994). What do we know about mathematics curricula? Journal of Mathematical Behaviour, 13(1), 55-80.

Science Community Representing Education, (2010) http:// www.nationalstemcentre.org.uk/res/documents/page/SCORE\%20report.pdf

Seirpinska, A. (1995). "In context", "pure", or "with applications"? A contribution to the question of transfer in the learning of mathematics, For the Learning of Mathematics, 15(1), 2-15.

Thornton, S. and Hogan, J., (2004a), Orientations to numeracy: teachers' confidence and disposition to use mathematics across the curriculum, Paper presented at the 28th Conference of the International Group for the Psychology of Mathematics Education, Bergen, Norway.

Thornton, S. and Hogan, J., (2004b), A perspective on numeracy (quantitative literacy), Paper presented at the Topic group 7: Mathematics in the Workplace. 10th International Congress on Mathematics Education, Copenhagen, Denmark. 